\title{
Avaliação como saber docente nos currículos das licenciaturas em Matemática
}

\author{
Nilson de Matos Silva \\ Plínio Cavalcanti Moreira
}

\section{Resumo}

Neste artigo, relata-se uma pesquisa em que são investigados os saberes sobre avaliação da aprendizagem escolar nos currículos de cursos de licenciatura em matemática no Brasil. Os dados foram produzidos a partir de uma busca on line das grades curriculares de 25 cursos de licenciatura em matemática de universidades públicas brasileiras. Esses dados fundamentaram a resposta que construímos para a questão: Como as instituições formadoras de professores de matemática para a Educação Básica no Brasil valorizam, nos seus currículos prescritos, os saberes a respeito da avaliação da aprendizagem escolar? Os resultados indicam que 22 dos 25 currículos pesquisados apresentam pelo menos uma disciplina obrigatória cuja ementa contém referências a essa temática, mas apenas dois deles propõem, nas ementas de suas disciplinas obrigatórias, um trabalho abrangente de formação do professor a respeito da avaliação da aprendizagem escolar. Nos currículos examinados, observa-se também a ausência de referências específicas às recomendações para o trabalho docente escolar com o tema expressas em documentos oficiais como PCN e Diretrizes Curriculares Nacionais para a Educação Básica.

Palavras-chave: Educação Matemática, Currículo de Licenciatura; Saber Docente; Avaliação da aprendizagem. 


\section{Assessment as teacher knowledge in mathematics teacher education}

Nilson de Matos Silva

Plínio Cavalcanti Moreira

\section{Abstract}

This work reports an investigation on mathematics teacher education curricula, related to knowledge about assessment in school classrooms. We start from a literature review on school assessment and then constructed an answer to the following research question: How Mathematics Teacher Education Programs in Brazil value knowledge concerning school assessment, according to their respective prescribed curriculum? Curricula of 25 Brazilian public institutions were analyzed and results indicate that knowledge about school assessment is not seen as highly relevant in the programs examined, except for two of them. It is important noticing also the absence of references, in the prescribed curricula, to recommendations expressed in Brazilian official documents such as PCN and Diretrizes Curriculares Nacionais para Educação Básica.

Keywords: Mathematics Education, Teacher Education; Teacher Knowledge; School Assessment. 


\section{Introdução}

No cenário brasileiro, as discussões envolvendo avaliação da aprendizagem em sala de aula passaram a ter maior visibilidade no final dos anos 1960 e início dos anos 1970, portanto, há cerca de cinquenta anos. Luckesi (2011, p.29) comenta a evolução da legislação brasileira e a passagem ao uso do termo avaliação da aprendizagem em nossos documentos legais: “A LDB, de 1961, ainda contém um capítulo sobre os exames escolares e a Lei $\mathrm{n}^{0}$ 5.692/71, que redefiniu o sistema de ensino no país, em 1971, deixou de utilizar a expressão "exames escolares" e passou a usar a expressão "aferição do aproveitamento escolar”, mas ainda não se serviu do termo "avaliação da aprendizagem”. Somente a LDB de 1996, se serviu dessa expressão no corpo legislativo” (destaques como no original).

Luckesi (2011) afirma, ainda, que a forma como se concebe e se realiza a avaliação reflete uma visão mais conservadora ou mais transformadora do papel social da escolarização. Dentro de um espectro relativamente amplo, mas não linear, uma visão mais conservadora se orientaria para um ensino fundamentado na transmissão de conhecimentos do professor (que sabe) para o aluno (que não sabe), concebendo a avaliação como uma medida da aprendizagem e a nota final como uma referência quantitativa ao que o aluno aprendeu (ou deixou de aprender). Em contraposição, pode-se identificar, entre outras, uma visão que concebe a formação escolar como parte importante da construção que o aluno faz de si mesmo, como sujeito social. Pensada nestes termos, a avaliação tomaria o caráter de elemento intrinsecamente vinculado a esse processo formativo, não se reduzindo a uma medida quantitativa do aprendizado passado de cada indivíduo.

As avaliações também podem ser vistas como um conjunto de obstáculos a serem ultrapassados para chegar ao diploma e às possibilidades de ascensão social potencialmente abertas por essa certificação. Tais obstáculos funcionariam como uma barreira a ser vencida em cada etapa da vida escolar, ameaçando atrasar ou impedir a consecução do objetivo de se formar e obter o diploma. Em suma, uma forma de pressão e, se bem dosada, de motivação, que visaria levar o aluno a se engajar no processo de formação escolar.

Segundo outra concepção ainda, que examina o processo escolar do ponto de vista da reprodução das relações capitalistas de produção, pode-se ver a avaliação escolar como uma forma de justificativa para o tipo de estratificação presente na sociedade capitalista, ou mais precisamente, como um critério de natureza meritocrática para a seletividade social inerente a esse processo de estratificação (Enguita, 1989). Quem não aprendeu, de acordo com os resultados da avaliação, não teria justificativas socialmente legítimas para aspirar a condições de emprego/trabalho iguais àquelas que estariam disponíveis para os que (supostamente) aprenderam. A avaliação, neste caso, projetaria uma conexão entre o desempenho atual no mundo da escola e o desempenho futuro no mundo do trabalho (e, portanto, no eventual 
posicionamento na escala social). Nesse sentido, sair-se bem nas avaliações seria visto como galgar os degraus de uma escada que levaria à ascensão social, cultural e/ou econômica.

Por fim, mas obviamente sem esgotar todo o espectro, a avaliação poderia ser vista também como uma forma de impor a submissão, acostumar o aluno a aceitar a autoridade, a fazer o que se espera que ele faça, uma forma de domesticação social, no dizer de Enguita (1989). Na escola, aceitar a autoridade do professor, que diz o que está certo e o que está errado, em nome do conhecimento. Mais tarde, no trabalho, aceitar a autoridade do chefe, que dá ordens e instruções, em nome da produção e do lucro.

Essas são apenas algumas das visões possíveis do papel da avaliação na escola, com reflexos na sociedade mais ampla. Há, como veremos adiante, muitos outros saberes associados ao trabalho docente com essa temática e a formação do professor não pode, a nosso ver, negligenciar a preparação para esse tipo de trabalho na escola porque, afinal, todo licenciado, no seu cotidiano profissional, terá que executar alguma forma de avaliação da aprendizagem matemática em sala de aula. Além disso, uma formação adequada no assunto pode estimular a busca de alternativas para as práticas avaliativas escolares habituais, ao mesmo tempo em que promove, pelo menos potencialmente, a percepção de limites mais claros para as possibilidades de implementar essas alternativas na prática docente concreta.

A questão da avaliação da aprendizagem (matemática) escolar é complexa e pode ter consequências importantes na promoção de um engajamento mais consistente do aluno no processo de aprendizagem, no encaminhamento do trabalho de ensino do professor e na eventual contribuição para o alcance dos objetivos educacionais. Isso não significa, para nós, que haja uma forma tecnicamente (ou politicamente) correta de avaliação da aprendizagem escolar e que o professor deva aprender essa forma no seu curso de licenciatura. Nossa visão é a de que o licenciando certamente necessita refletir sobre esse aspecto de sua futura prática profissional durante o processo de formação inicial.

A partir da perspectiva exposta acima, desenvolvemos uma pesquisa que investigou a presença de saberes sobre avaliação da aprendizagem escolar nos currículos de 25 cursos de licenciatura em matemática de universidades públicas brasileiras. Na próxima seção, apresentamos uma revisão da literatura sobre a temática da avaliação da aprendizagem na escola, incluindo alguns documentos oficiais brasileiros, destacando elementos que nos ajudaram na categorização dos dados obtidos a partir do exame dos currículos prescritos dos cursos de licenciatura em matemática da nossa amostra. Na terceira seção deste artigo descrevemos os procedimentos metodológicos utilizados e apresentamos nossa resposta à seguinte questão de pesquisa: Como as instituições formadoras de professores de matemática para a Educação Básica no Brasil valorizam, nos seus currículos prescritos, os saberes a 
respeito da avaliação da aprendizagem escolar? Na última seção, fazemos uma discussão dos resultados encontrados.

\section{A literatura especializada e os documentos oficiais brasileiros}

Considerando o cenário internacional, especialmente o norte-americano, no qual se desenvolveram de modo particularmente intenso os estudos a respeito das avaliações, um pesquisador que se destaca é Ralph Tyler. As visões vigentes sobre o tema no século XX receberam o impacto da sua obra, a qual influenciou também a pesquisa posterior e contribuiu para a formação de uma cultura mundial acerca da avaliação educacional (Luckesi, 2011). O ponto principal dos estudos de Tyler sobre currículo e avaliação reside na defesa de uma cuidadosa formulação de objetivos educacionais e de uma organização da experiência de aprendizagem com base em critérios fundamentados na Psicologia. A avaliação, em última instância, teria seu fundamento em um processo de comparação entre os dados de desempenho escolar e os objetivos instrucionais preestabelecidos (Tyler, 1949). Para este autor, o desenvolvimento concreto do processo de ensino escolar envolve inúmeras variáveis (as características individuais dos estudantes, a habilidade do professor em criar um ambiente de aprendizagem adequado, a competência geral de cada professor para o planejamento e a execução das ações de ensino etc.). Seria impossível, ainda segundo Tyler, garantir que as experiências de aprendizagem que acontecem efetivamente na prática escolar sejam precisamente aquelas planejadas, propostas e organizadas no currículo. Assim, um processo de avaliação torna-se necessário, mesmo após um esmerado planejamento. Tyler vê, então, a avaliação como um processo que visa determinar se os objetivos educacionais estão sendo alcançados. Entretanto, ainda de acordo com Tyler, como esses objetivos visam produzir mudanças nos padrões comportamentais do estudante, a avaliação se ocuparia de determinar o nível em que essas mudanças de comportamento desejáveis estariam efetivamente ocorrendo.

Segundo Hoffmann (2003), no Brasil há forte influência do modelo desenvolvido por Tyler. Mesmo propostas bem posteriores, e recebidas com certo entusiasmo aqui, como, por exemplo, a de Bloom, Engelhart, Furst, Hill, Krathwhol (1977), mantêm essa orientação de fundo behaviorista, conforme comenta Vieira (2006, p.25).

Uma questão importante, que poderia servir como um divisor de águas, quando tratamos das concepções a respeito da avaliação da aprendizagem escolar, é a seguinte: é possível medir a aprendizagem? Baldino (1994) defende a ideia de que as avaliações escolares não são realizadas, de fato, para se obter uma medida da aprendizagem, como se propaga em determinados discursos sobre o tema, mas têm como real objetivo demarcar parâmetros para a promoção. Para esse autor, a aprendizagem matemática, constituindo um processo 
complexo, interno a cada indivíduo, não é suficientemente acessível para ser medida com base em critérios de justiça e cientificidade. Ele diz: "As dificuldades na aplicação dos paradigmas da medida à avaliação da aprendizagem [...] se devem a que o sujeito humano não só interage com o medidor, como todo objeto medido, mas, além disso, tem interesse em que a medida acuse um certo valor" (Baldino, 1994, p.2).

Embora não seja explicitado no discurso escolar, haveria, segundo Baldino, interesses de ordem política em criar certa identificação entre as ideias de promoção e de avaliação quantitativa da aprendizagem, com reflexos nas práticas pedagógicas. Avaliar a aprendizagem quantitativamente seria medir o que o aluno aprendeu ou deixou de aprender num determinado processo de ensino, o que, como vimos acima, Baldino classifica como uma tarefa muito difícil, se não impossível. Outra coisa, seria estabelecer critérios para a promoção dentro das etapas seriadas da escolarização. Mais precisamente, a crítica desse autor vai no sentido de que, na medida em que se confunde avaliação da aprendizagem com promoção, deixa-se fora de foco a questão da natureza dos critérios segundo os quais o aluno é promovido ou reprovado, pressupondo-se a "justiça" inerente à ideia de que o aluno foi reprovado porque não aprendeu o suficiente, quando outros aprenderam e, consequentemente, foram aprovados. Para Baldino (1995), a questão da promoção é crucial para o aluno, na medida em que a conquista do diploma confere mais valor à sua força de trabalho, agora qualificada, incorporando certo tempo de trabalho social na sua produção e, portanto, segundo uma visão marxista do valor das mercadorias, incorporando também, eventualmente, maior valor de troca a essa força de trabalho, no mercado de mão de obra.

Podemos propor assim, assumindo as limitações da perspectiva naive que orienta nossa proposta, o agrupamento das ideias relacionadas ao papel e ao sentido da avaliação da aprendizagem na educação escolar em três grandes vertentes (não necessariamente disjuntas): i) aquelas que veem a avaliação escolar a partir da ideia de precisa (o mais possível, pelo menos) medida da aprendizagem e, consequentemente, como justo (o mais possível) critério de aprovação/reprovação; ii) as que concebem a avaliação essencialmente como parte das práticas escolares que se submetem à lógica geral da reprodução das relações capitalistas de produção; iii) aquelas que veem no processo de avaliação escolar a oportunidade de coleta de informações que se voltam para a crítica e, eventualmente, para a melhoria do planejamento, da organização e do desenvolvimento dos processos de ensino e de aprendizagem (avaliação formativa).

A ideia geral de avaliação formativa é importante, entre outras razões, porque é ela que vai orientar o discurso dos documentos oficiais brasileiros das últimas décadas sobre essa temática, como veremos logo adiante. Segundo Luckesi (2011), a proposta de avaliação formativa fundamenta-se na observação e no registro do desenvolvimento dos alunos, em seus 
aspectos cognitivos, afetivos e relacionais, decorrentes das propostas de ensino executadas; segundo seus defensores, deve ser contínua, diagnóstica, sistemática e constituir o eixo central dos processos de ensino e de aprendizagem. Deve fazer parte do cotidiano da sala de aula e ser contemplada em cada situação de aprendizagem proposta pelo professor e realizada pelo aluno; deve possibilitar revisar todos os passos do planejamento e pressupõe que a escola, ao avaliar seus alunos, avalie-se também como instituição. De acordo com essa concepção, para realizar a avaliação formativa deve-se ter padrões claramente estabelecidos do que é necessário aprender e do caráter significativo e funcional do conhecimento trabalhado, de modo que o aluno possa "aplicá-lo" em seu contexto de desenvolvimento pessoal; devem-se criar mecanismos para verificar como cada aluno conseguiu interagir com o que foi proposto e mecanismos para reconstruir o processo, caso não tenha havido um desempenho satisfatório.

Há, na literatura, muitas propostas de práticas avaliativas em matemática, alternativas às provas escritas usuais, em que se utilizam estratégias específicas de avaliação para os diversos tópicos matemáticos do ensino escolar (ver, por exemplo, Kajander, Holm e Chernoff, 2018, Part V). Por outro lado, Arnal-Bailera, Cid, Muñoz-Escolano e Oller-Marcén (2016) estudaram os efeitos da subjetividade (especialmente as diferenças de formação em diferentes cursos de graduação) na forma como os professores avaliam as respostas dos alunos em provas escritas de matemática. Há também uma parte da literatura que aborda questões sobre avaliação da aprendizagem matemática relacionadas a gênero, grupos sociais minoritários ou economicamente subalternos, enfim, questões relacionadas ao papel da avaliação escolar em matemática nos processos de inclusão e equidade em geral (p.ex., Nortvedt e Buchholts, 2018).

Vê-se, assim, que a questão da avaliação da aprendizagem e da preparação do professor para seu planejamento e execução na sala de aula de matemática da escola é complexa e merece atenção no processo de formação profissional docente. Entretanto, por um motivo ou por outro, o que parece predominar na prática escolar efetiva é uma visão simplista e naturalizada da avaliação da aprendizagem, concebida como medida da aprendizagem passada, com as consequências restritas ao veredicto quantitativo que leva usualmente à aprovação ou reprovação em cada disciplina (Lopes, 2016). É importante observar, por outro lado, que o questionamento dessa visão dominante conduz a uma demanda de saberes profissionais docentes específicos sobre a avaliação da aprendizagem escolar. Assim, é fundamental que o futuro professor de matemática da Educação Básica possa ter acesso, na sua formação inicial, a saberes essenciais para a construção de uma visão crítica das diversas concepções a respeito do processo de avaliação das aprendizagens escolares e a saberes pertinentes ao desenvolvimento das correspondentes práticas avaliativas e de suas limitações, considerando o contexto escolar concreto. Isso abriria a possibilidade de aderir 
conscientemente a alguma(s) dessas concepções, rejeitar, questionar ou adaptar outras alternativas, e ter condições de, quando possível, selecionar, planejar e por em execução, de forma consistente, os instrumentos associados à(s) correspondente(s) forma(s) de avaliação da aprendizagem a que tenha aderido.

\title{
O que dizem os Parâmetros Curriculares Nacionais para a Educação Básica e as Diretrizes para a Licenciatura
}

Na Introdução aos Parâmetros Curriculares Nacionais $1^{\text {a à }} 4^{\text {a }}$ série, Brasil (1997), afirma-se que a avaliação da aprendizagem escolar deve ter uma função formativa, que constituiria "parte integrante e intrínseca ao processo educacional" (p.52). Além dessa, teria também a função de oferecer subsídios, através de seus resultados, para a certificação escolar (aprovação em séries/anos/ciclos e obtenção do certificado ao final de cada nível de ensino Fundamental ou Médio). No corpo do referido documento, enfatiza-se a função formativa, destacando-se a ideia de um processo contínuo e sistemático, em oposição a uma ocorrência formal "após o fechamento das etapas do trabalho, como é o habitual” (idem, p.52).

O documento Brasil (1997) insiste ainda na necessidade de se estabelecerem claramente as expectativas de aprendizagem, através de critérios de avaliação adequados para cada ciclo, para cada ano e para cada etapa do trabalho pedagógico, dentro de um mesmo ano:

\begin{abstract}
No caso da avaliação escolar, é necessário que se estabeleçam expectativas de aprendizagem dos alunos em consequência do ensino, que devem se expressar nos objetivos, nos critérios de avaliação propostos e na definição do que será considerado como testemunho das aprendizagens. Do contraste entre os critérios de avaliação e os indicadores expressos na produção dos alunos surgirá o juízo de valor, que se constitui a essência da avaliação (p. 58, grifo nosso).

Os critérios não expressam todos os conteúdos que foram trabalhados no ciclo, mas apenas aqueles que são fundamentais para que se possa considerar que um aluno adquiriu as capacidades previstas de modo a poder continuar aprendendo no ciclo seguinte, sem que seu aproveitamento seja comprometido (p. 58).

[...] A aprovação ou a reprovação é uma decisão pedagógica que visa garantir as melhores condições de aprendizagem para os alunos. [...] Para tal decisão é importante considerar, simultaneamente aos critérios de avaliação, os aspectos de sociabilidade e de ordem emocional, para que a decisão seja a melhor possível, tendo em vista a continuidade da escolaridade sem fracassos (p. 59).
\end{abstract}

Por sua vez, os Parâmetros Curriculares Nacionais - Terceiro e Quarto Ciclos do Ensino Fundamental - Matemática Brasil (1998), em harmonia com essa visão de avaliação do documento relativo aos anos iniciais de escolarização (e mantendo sempre como referência a lei maior que é a LDBEN - Brasil, 1996 - especialmente os seus artigos 13, 24, 31, 32 e 36) define os critérios de avaliação em matemática para o terceiro e quarto ciclo, observando que, 
"ainda que [os critérios] indiquem o tipo e o grau de aprendizagem que se espera que os alunos tenham realizado a respeito dos diferentes conteúdos, apresentam formulação suficientemente ampla como referência para as adaptações necessárias em cada escola, de modo que possam se constituir em critérios reais para a avaliação" (Brasil, 1998, p.76).

Como se pode notar, as recomendações dos PCN sobre o desenvolvimento do processo de avaliação da aprendizagem matemática em cada sala de aula de cada escola pressupõem o domínio, por parte do professor, de um grande volume de conhecimentos matemáticos, didáticos, pedagógicos, psicológicos etc. na interface com saberes relativos às diferentes concepções, modalidades, meios e instrumentos de avaliação da aprendizagem escolar. Ainda que as Diretrizes Curriculares Nacionais para a Formação de Professores da Educação Básica, em nível superior, curso de licenciatura, de graduação plena (Brasil, 2001a), assim como as Diretrizes Curriculares Nacionais para os Cursos de Matemática, Bacharelado e Licenciatura (Brasil, 2001b) não mencionem explicitamente, como conhecimentos e competências a serem promovidos pelo currículo de formação, os saberes relacionados a esse tema, insistimos que saberes docentes específicos são demandados no exercício das práticas avaliativas escolares, especialmente se a escola e os professores se propõem a acatar as orientações dos PCN quanto ao planejamento e execução das avaliações da aprendizagem escolar em matemática.

Para dar um exemplo, ao se propor a definir, com precisão e clareza, como demandam os documentos Brasil (1997) e Brasil (1998), as concretizações de critérios de avaliação referentes ao desenvolvimento do pensamento algébrico e o correspondente domínio da linguagem e da simbologia algébricas na Educação Básica (citados aqui apenas como um caso ilustrativo), é preciso que o professor mobilize conhecimentos profissionais bastante diversificados. Tais conhecimentos devem lhe permitir, entre outras especificidades relacionadas a esses critérios de avaliação, distinguir diferentes etapas de desenvolvimento do pensamento algébrico e do processo de generalização.

Para citar apenas dois grupos dessas etapas, destacamos: a) aquelas nas quais os símbolos utilizados para expressar ideias ligadas aos processos de abstração e generalização algébricas são utilizados, nos anos iniciais e no início do terceiro ciclo do EF, num nível mais personalizado, como desenhos, convenções específicas para uma dada sala de aula, termos dêiticos etc.; b) aquelas etapas (ao final do quarto ciclo do EF ou já no Ensino Médio) em que uma linguagem mais universal, compacta e operacionalmente mais adequada já deveria estar internalizada (cf. Radford, 2009, 2010, 2011). Isso sem considerar outras recomendações dos PCN quanto às expectativas de aprendizagem e critérios de avaliação, como, por exemplo:

"Os critérios de avaliação devem permitir concretizações diversas por meio de diferentes indicadores; assim, além do enunciado que os define, deverá haver um breve comentário explicativo que contribua para a identificação de 
indicadores nas produções a serem avaliadas, facilitando a interpretação e a flexibilização desses critérios, em função das características do aluno e dos objetivos e conteúdos definidos" (Brasil, 1997, p.58).

Ainda devemos considerar que o futuro professor de matemática da escola deve estar preparado para vivenciar situações exigentes, como as do exemplo concreto citado acima, em diferentes estágios e níveis da educação escolar e relacionadas com a avaliação da aprendizagem em diferentes tópicos da disciplina (o estudo das funções, da geometria, dos conjuntos numéricos, do tratamento da informação etc., desde o sexto ano do Ensino Fundamental até o terceiro do Ensino Médio, sem falar em diferentes momentos dentro do mesmo ano de escolaridade). Além disso, espera-se que o professor possua uma visão clara dos objetivos da formação escolar, tanto gerais, da instituição como um todo, como aqueles específicos da formação na disciplina Matemática.

Neste último caso, deve possuir uma visão global da matemática escolar que lhe permita colocar ênfase, em suas propostas de práticas avaliativas de sala de aula, nos aspectos fundamentais do desenvolvimento escolar do aluno (p. ex., a capacidade de usar flexivelmente o conhecimento aprendido, de modo a desenvolver estratégias de resolução de problemas, adaptando-as a situações "novas"; à capacidade de entender e comunicar ideias utilizando os conceitos e a linguagem matemática etc.) e não apenas nos aspectos relativos à reprodução de procedimentos algorítmicos e "aplicação" mecânica dos fatos matemáticos em exercícios rotineiros e padronizados. Assim, pode-se inferir que os Parâmetros Curriculares Nacionais, em conformidade com o disposto no artigo 24 da LDBEN Brasil (1996), supõem que o professor da Educação Básica seja capaz de mobilizar conhecimentos complexos e diversificados, ao planejar e executar o trabalho docente referente às tarefas de avaliação da aprendizagem escolar.

Isso, implica, evidentemente, a necessidade de trabalhar esses conhecimentos no processo de formação na licenciatura. Ao mesmo tempo, seria, sem dúvida, desejável que o processo de formação do licenciando promovesse um olhar crítico para as próprias recomendações específicas dos $\mathrm{PCN}$ a respeito do tema avaliação das aprendizagens na escola, o que pressupõe o acesso a percepções críticas devidamente fundamentadas das diferentes concepções, modalidades, meios e instrumentos de avaliação em sala de aula da escola. Por exemplo, o processo de formação poderia promover discussões qualificadas a respeito de questões como: em que medida é possível cumprir, na prática docente escolar, as recomendações quanto aos elementos formativos da avaliação em sala de aula (processo contínuo, sistemático, integrado intrinsecamente ao ensino e à aprendizagem etc.), se a escola, como instituição, nem sempre se mostra flexível na consideração efetiva de aspectos fundamentais associados a essa modalidade de avaliação, tais como "possibilitar revisar todos 
os passos do planejamento”, “ao avaliar seus alunos, avalie-se também como instituição”, "criar mecanismos para verificar como cada aluno conseguiu interagir com o que foi proposto e mecanismos para reconstruir o processo, caso não tenha havido um desempenho satisfatório"?

Além disso, partindo do questionamento de Baldino (1994) já comentado, é preciso levar o licenciando a refletir a respeito de questões sobre como avaliar efetivamente o progresso da aprendizagem do aluno, através de indicadores e instrumentos com os quais o mesmo aluno interage, tendo interesse direto no resultado da avaliação. Entendemos que esses (e outros) são problemas de dimensão suficientemente grande para que o processo de formação do professor não se permita deixar que o equacionamento deles fique por conta pessoal do licenciado, e que se desenvolva a partir apenas da sua futura experiência direta em sala de aula da escola. Em outras palavras, é preciso preparar o futuro professor tanto para seguir as recomendações institucionais, como para questioná-las, quando for o caso. E, evidentemente, qualquer que seja o caso, fazê-lo com a devida fundamentação.

Esperamos ter construído um argumento em defesa da ideia de que os saberes sobre a avaliação da aprendizagem matemática escolar fazem parte efetiva da prática do professor de matemática, contendo, pelo menos potencialmente, elementos que se agregariam aos componentes disciplinares, didáticos e pedagógicos do saber profissional docente. No entanto, apesar da existência de uma literatura relativamente extensa sobre as questões referentes à preparação do professor para as tarefas de avaliação da aprendizagem escolar e, mais geralmente, para o desenvolvimento de uma competência diagnóstica no exercício da docência (Leuders, Philipp e Leuders, 2018), observamos uma espécie de vácuo nos estudos específicos sobre os saberes docentes a respeito do papel da avaliação da aprendizagem escolar, suas modalidades e instrumentos, bem como em relação a outros saberes associados ao planejamento e execução das práticas avaliativas escolares em matemática. Conjecturamos, então, que tal vácuo pudesse se estender aos currículos dos cursos de formação inicial dos professores de matemática. Nesse sentido, entendemos que ganha relevância, no cenário da pesquisa brasileira sobre o tema, este nosso estudo, no qual fazemos um levantamento da importância dada aos saberes sobre avaliação pelos currículos prescritos de 25 cursos de licenciatura em matemática oferecidos por universidades públicas brasileiras.

Na revisão de literatura que acabamos de apresentar acima, procuramos destacar, ainda que abreviadamente, um conjunto de elementos que fundamentam nossa reivindicação de que é necessário que o futuro professor se prepare, tanto do ponto de vista prático como teórico, para contribuir na tomada de decisões institucionais a respeito da política geral de avaliação da aprendizagem na escola, bem como para planejar e executar as práticas avaliativas específicas em suas salas de aula. Assim, essa revisão da literatura nos ajuda, em primeiro 
lugar, a situar nosso estudo, cujo foco é a questão da preparação do futuro professor, nos cursos de licenciatura em matemática, para o planejamento e execução das práticas de avaliação da aprendizagem que terá necessariamente de realizar no exercício da docência escolar. Em segundo lugar, essa revisão tem a função de estabelecer as referências básicas que tivemos em mente ao analisar os currículos prescritos selecionados, a fim de responder a pergunta de investigação que apresentamos no final da Introdução, qual seja: Como as instituições formadoras de professores de matemática para a Educação Básica no Brasil valorizam, nos seus currículos prescritos, os saberes a respeito da avaliação da aprendizagem escolar?

\section{Os procedimentos metodológicos e os resultados}

Nesta seção, descrevemos os procedimentos metodológicos utilizados para construir nossa resposta para a questão de pesquisa apresentada acima. Antes, no entanto, julgamos importante observar que, nos documentos oficiais que regulamentam a formação docente para a Educação Básica por nós examinados, não se faz referência à obrigatoriedade de que conste dos currículos das licenciaturas (ementas de disciplinas, por exemplo) o trabalho formativo específico com os conhecimentos associados ao planejamento e à execução das (futuras) práticas avaliativas escolares. O documento Diretrizes Curriculares Nacionais para a Formação de Professores da Educação Básica, em nível superior, curso de licenciatura, de graduação plena (Brasil, 2001b), por exemplo, trata da avaliação da aprendizagem apenas como processo a ser executado nos próprios cursos de licenciatura, comentando algumas dificuldades específicas dessa execução e oferecendo sugestões para superá-las, sempre em acordo com as referências gerais sobre o assunto, contidas na LDBEN Brasil (1996) e nos PCN Brasil (1997, 1998):

Tendo a atuação do professor natureza complexa, avaliar as competências no processo de formação é, da mesma forma, uma tarefa complexa (p.34).

[...] A avaliação deve ser realizada mediante critérios explícitos e compartilhados com os futuros professores, uma vez que o que é objeto de avaliação representa uma referência importante para quem é avaliado, tanto para a orientação dos estudos como para a identificação dos aspectos considerados mais relevantes para a formação em cada momento do curso (Brasil, 2001b, p.40).

Assim, sem referência à preparação dos futuros professores para as práticas escolares de avaliação da aprendizagem escolar, as Diretrizes deixam as instituições formadoras livres de qualquer normativa sobre o desenho do currículo dos cursos de licenciatura em matemática, no que se refere a esse ponto.

Observado isso, passemos aos procedimentos metodológicos. Os currículos dos cursos de licenciatura em matemática das instituições pesquisadas foram obtidos nos sites das 
universidades que compuseram a nossa amostra, com acessos no segundo semestre de 2013. No entanto, em 2017, voltamos a acessar os respectivos sites, em função de havermos percebido a ocorrência de mudanças em alguns dos currículos estudados em 2013, o que nos levou a ajustes e atualizações nos dados utilizados neste artigo.

A busca documental das informações via internet representou uma opção interessante para a pesquisa, pois abriu a possibilidade de ampliação significativa da amostra. Assim, pudemos examinar os currículos de várias universidades que mantêm seus projetos pedagógicos do curso (Licenciatura em Matemática) disponíveis na internet e selecionamos 16 universidades federais da região sudeste (UFMG, UFOP, UFV, UFSJ, UFVJM, UNIFEI, UFU, UFTM, UNIFAL, UFJF, UFRJ, UFRRJ, UNIRIO, UFSCar, UFABC, UFES), três das estaduais paulistas (USP/SP, UNICAMP e UNESP-RC) e, para completar, contemplando, ainda que de forma limitada, todas as regiões geográficas do país, selecionamos também a Universidade Federal do Pará (UFPA), a Universidade Federal de Pernambuco (UFPE - Campus Recife), a Universidade Federal do Rio Grande do Sul (UFRGS), a Universidade Federal do Mato Grosso (UFMT) e a Universidade de Brasília (UnB). Compusemos então uma amostra com um total de 25 universidades, uma vez que foi acrescentada a Universidade Estadual de Minas Gerais (UEMG - Ibirité). A inclusão da UEMG foi especialmente importante para outros estudos que compuseram a pesquisa, mas que não são relatados neste trabalho. A centralização das instituições pesquisadas na região sudeste ocorreu em função da proximidade geográfica com os locais de trabalho dos autores, permitindo o acesso facilitado, caso necessitássemos comparecer presencialmente a essas instituições para dirimir eventuais dúvidas, complementar a produção de dados etc. (o que efetivamente ocorreu, em um ou outro caso).

Após análise, os currículos foram classificados em quatro categorias, construídas a posteriori. Assim, na medida em que as leituras e releituras dos dados foram tornando possível captar as regularidades e cotejá-las com as indicações da literatura especializada sobre o tema, as categorias de natureza essencialmente qualitativa foram emergindo, sendo dispostas segundo a classificação descrita a seguir:

- Grupo A - Relevância Alta - currículos que apresentam pelo menos uma disciplina obrigatória cuja ementa é consistente com os diversos aspectos (teóricos e práticos) apontados pela literatura como relevantes no tratamento do tema, incluindo referências bibliográficas correspondentes.

- Grupo B - Relevância Média - currículos que apresentam os saberes sobre a avaliação da aprendizagem escolar como tópicos dispersos em ementa(s) de disciplina(s) obrigatória(s), sendo que nas referências bibliográficas aparecem textos consistentes com os tópicos relativos ao tema. No entanto, cotejados com os currículos do grupo A, esses tópicos, 
em seu conjunto, não compõem uma proposta de abordagem equivalente àquela prescrita nos currículos do Grupo A.

- Grupo C - Relevância Baixa - Os saberes sobre a avaliação da aprendizagem escolar constam como tópicos dispersos em ementas de disciplinas do currículo, porém nas referências bibliográficas recomendadas não aparecem textos que tratem especificamente do assunto. $\mathrm{Ou}$, alternativamente, há referências bibliográficas sobre o tema, mas a(s) disciplina(s) não é (são) obrigatória(s) (são optativas ou eletivas).

A classificação construída teve como base, conforme mencionado acima, a revisão de literatura e a leitura que fizemos das recomendações dos documentos oficiais, portanto tratase, como já destacamos, de uma categorização elaborada a partir de parâmetros essencialmente qualitativos. A referência quantitativa (pelo menos uma disciplina obrigatória) é apenas para demarcar o mínimo aceitável no Grupo A, mas esse mínimo deve estar conjugado com as exigências de natureza qualitativa (ver itens a-g, logo abaixo), como explicitado nas descrições de cada um dos Grupos A, B e C. Podemos sintetizar os elementos gerais de saber sobre avaliação da aprendizagem que tomamos como base para essa classificação da seguinte maneira:

a) O estudo das diferentes concepções (e/ou teorias) relativas à avaliação da aprendizagem, incluindo uma visão do desenvolvimento histórico delas.

b) $\mathrm{O}$ estudo das relações da avaliação da aprendizagem matemática com o sucesso/fracasso escolar.

c) O estudo das relações entre avaliação, ensino e aprendizagem, especialmente no caso da matemática.

d) O estudo da função social da avaliação da aprendizagem escolar e de suas funções específicas nos processos de ensino e de aprendizagem.

e) O estudo do papel atribuído aos erros (cometidos pelos alunos) nas diferentes modalidades de avaliação da aprendizagem escolar.

f) O estudo da elaboração de critérios de avaliação da aprendizagem escolar, da identificação das expectativas e indicadores de aprendizagem, a partir dos objetivos formativos e das estratégias de ensino em cada momento do processo de escolarização.

g) Experiências de elaboração, aplicação, correção e discussão de diferentes instrumentos de avaliação da aprendizagem, coerentes com as respectivas modalidades de avaliação e com as especificidades da matemática, entendida como disciplina escolar.

No geral, podemos dizer que os currículos do grupo A contemplam, em disciplinas obrigatórias, essencialmente, os itens listados acima, com algumas exceções que especificaremos mais adiante; os do grupo B, ao dispersarem os tópicos entre disciplinas não específicas sobre o tema, contemplam apenas parcialmente a lista tomada como base de 
referência. Os do grupo C contemplam alguns dos tópicos, mas sem a devida consistência, uma vez que o fazem apenas em ementas de disciplinas não obrigatórias ou, alternativamente, sem nem mesmo relacionar referências bibliográficas para os tópicos contemplados nessas ementas.

Não encontramos, nos currículos examinados, casos em que os elementos de conhecimento profissional sobre o tema, listados acima (a-g), estivessem cobertos no mesmo nível dos currículos do Grupo A, ainda que dispersos entre outros tópicos de disciplinas obrigatórias, tais como Didática, Estágios Supervisionados, Prática de Ensino etc.

A seguir apresentamos a composição final de cada um dos grupos, em termos da amostra considerada nesta pesquisa, fundamentando a classificação a partir de dados obtidos no exame dos currículos dos cursos estudados.

Grupo C - Relevância Baixa (UNIFAL; UFJF; UFV; UFABC; UFMG; UEMG Ibirité; UFOP. Tais instituições compõem $28 \%$ da amostra). No caso dos cinco primeiros currículos deste grupo, a avaliação consta como tópico em ementas de disciplinas obrigatórias, porém nas respectivas referências bibliográficas não aparecem textos que tratem do assunto. No caso dos dois últimos, há referências bibliográficas na ementa, mas a disciplina correspondente não é obrigatória (é eletiva ou optativa).

GRUPO B - Relevância Média (UFSCar; USP; UFU; UFVJM; UFRJ; UNICAMP; UNESP/RC; UFPA; UnB; UFRGS; UNIFEI; UNIRIO; UFMT; UFSJ; UFES; UFRRJ. Compõem $64 \%$ da amostra). No caso dos onze primeiros currículos, cada um deles possui uma disciplina obrigatória, cuja ementa cita, em seus tópicos, alguns que se aproximam de itens da relação tomada como base para a classificação, embora não contemple a lista como um todo de modo minimamente abrangente. Em todos os casos há referências bibliográficas que se ajustam aos tópicos referidos nas ementas. Os currículos das cinco últimas possuem, cada um deles, mais de uma disciplina obrigatória cujas ementas contêm tópicos referentes ao tema. No entanto, analisando as ementas dessas disciplinas obrigatórias, levando em consideração as correspondentes cargas horárias, as referências bibliográficas e os demais tópicos que compõem essas ementas, avaliamos que não há equivalência, nos termos desta pesquisa, entre esses currículos e os que compõem o GRUPO A, descritos logo abaixo.

GRUPO A - Relevância alta (UFTM; UFPE; 8\% da amostra). No currículo do curso da UFTM há uma (única) disciplina obrigatória que, embora ocupando o tempo curricular de apenas 30 horas e 2 créditos (num total de 3720 horas e 248 créditos do curso completo), trata especificamente da avaliação da aprendizagem, com uma ementa relativamente ampla (contrastada com os itens referenciais da nossa categorização) e com referências bibliográficas compatíveis com os tópicos relacionados. Por isso esse currículo foi classificado no Grupo A. Fica em aberto, no entanto, a questão da possibilidade efetiva de cobrir todos os tópicos da 
ementa, com a profundidade adequada, em apenas 30 horas do curso de formação. Interpretamos a existência dessa disciplina obrigatória no currículo como uma tentativa (todavia tímida, a nosso ver) de destacar a importância do tratamento específico do tema num curso de Licenciatura em Matemática. Vejamos em detalhes a ementa desta disciplina:

Avaliação Educacional (disciplina obrigatória, 30 horas, sexto período) Ementa: As teorias sobre a avaliação da aprendizagem. As relações da avaliação com a didática e com a aprendizagem. Questões ideológicas nos processos de avaliação. As políticas de avaliação no Brasil. Tipos de avaliação. Avaliação somativa vs avaliação formativa. Técnicas, procedimentos e instrumentos de avaliação. Os critérios de avaliação. Prática de elaboração, aplicação e correção de diferentes instrumentos de avaliação na sala de aula.

Como se vê, a ementa acima, embora cubra boa parte dos itens da lista básica que nos serve de referência, não se refere explicitamente, em nenhum de seus tópicos a qualquer especificidade do tema em relação à disciplina Matemática. Por outro lado, não contempla de modo completo as recomendações dos documentos oficiais analisados.

Quanto ao currículo do curso da UFPE (campus Recife), temos uma disciplina obrigatória específica sobre o tema (veja ementa abaixo) e mais duas disciplinas (uma de 90 horas e outra de 105 horas - 45 teóricas e 60 de prática) onde se encontram referências a tópicos relativos ao tema. Apresentamos abaixo a ementa da disciplina específica sobre o tema, seguida dos tópicos das outras duas não específicas:

Avaliação da Aprendizagem (obrigatória, 6o horas, sexto período).

Ementa: Estudo da avaliação da aprendizagem, estudo da avaliação da aprendizagem enquanto objeto de reflexão do campo da avaliação educacional. A constituição de seu campo conceitual e praxiológico, os diferentes atributos e modos de conceber e praticar a avaliação das aprendizagens dos alunos.

Em outra disciplina obrigatória, Estágio Supervisionado em Matemática 2 (105 horas, sexto período), a ementa refere-se a outro tópico complementar aos da ementa da disciplina específica: estudo da aula de matemática em sua especificidade: planejamento, desenvolvimento e avaliação. Finalmente, uma terceira disciplina obrigatória, Metodologia do Ensino de Matemática 1 (segundo período, 90 horas) faz menção, em sua ementa, ao seguinte tópico: Estudo da avaliação da aprendizagem matemática. Como se pode notar, a disciplina específica Avaliação da Aprendizagem trata do tema de um ponto de vista geral, independente da matemática, e as duas outras elaboram parte das especificidades do tema, quando visto sob a ótica particular da disciplina Matemática. 


\section{Uma síntese geral dos resultados}

A seguir, apresentamos, no QUADRO 1, a lista das instituições cujos currículos foram examinados nesta pesquisa, sintetizando os resultados obtidos.

Quadro 1: Avaliação como saber docente nos currículos de Licenciatura em Matemática

\begin{tabular}{|c|c|c|c|c|}
\hline 苛 & Instituições & $\begin{array}{c}\% \text { do total } \\
\text { da amostra }\end{array}$ & Sigla & Disciplina(s) \\
\hline $\mathbf{A}$ & $\begin{array}{ll}\text { Universidade Federal } & \text { do } \\
\text { Triângulo Mineiro } & \end{array}$ & \multirow{2}{*}{$8 \%$} & UFTM & Avaliação Educacional \\
\hline $\mathbf{A}$ & \begin{tabular}{|lll} 
Universidade & Federal & de \\
Pernambuco & & \\
\end{tabular} & & UFPE & $\begin{array}{l}\text { Avaliação da Aprendizagem } \\
\text { (mais tópicos em outras duas) }\end{array}$ \\
\hline B & \begin{tabular}{|lll} 
Universidade & Federal de São \\
João del Rey & & \\
\end{tabular} & \multirow{16}{*}{$64 \%$} & UFSJ & Diversas \\
\hline $\mathbf{B}$ & $\begin{array}{|lll|}\begin{array}{l}\text { Universidade } \\
\text { Carlos }\end{array} & \text { Federal de São } \\
\end{array}$ & & UFSCar & Didática \\
\hline B & \begin{tabular}{|lcc} 
Universidade & Federal & de \\
Uberlândia & & \\
\end{tabular} & & UFU & Didática \\
\hline $\mathbf{B}$ & $\begin{array}{l}\text { Universidade Federal do Estado } \\
\text { do Rio de Janeiro }\end{array}$ & & UNIRIO & Didática \\
\hline $\mathbf{B}$ & $\begin{array}{l}\text { Universidade Federal do Rio de } \\
\text { Janeiro }\end{array}$ & & UFRJ & Didática \\
\hline B & $\begin{array}{l}\text { Universidade Federal do Rio } \\
\text { Grande do Sul }\end{array}$ & & UFRGS & $\begin{array}{l}\text { Organização curricular, } \\
\text { planejamento e avaliação }\end{array}$ \\
\hline B & $\begin{array}{ll}\text { Universidade } & \text { Estadual } \\
\text { Paulista/Rio Claro } & \\
\end{array}$ & & $\begin{array}{c}\text { UNESP/R } \\
\mathrm{C} \\
\end{array}$ & Didática \\
\hline $\mathbf{B}$ & Universidade de São Paulo & & USP & Didática \\
\hline $\mathbf{B}$ & Universidade Federal do Pará & & UFPA & Didática \\
\hline $\mathbf{B}$ & $\begin{array}{l}\text { Universidade Federal do Mato } \\
\text { Grosso }\end{array}$ & & UFMT & Didática \\
\hline $\mathbf{B}$ & Universidade de Brasília & & UNB & Didática Fundamental \\
\hline B & $\begin{array}{l}\text { Universidade Federal dos Vales } \\
\text { do Jequitinhonha e Mucuri }\end{array}$ & & UFVJM & Metodologia do Ensino \\
\hline $\mathbf{B}$ & $\begin{array}{l}\text { Universidade Estadual de } \\
\text { Campinas }\end{array}$ & & UNICAMP & $\begin{array}{c}\text { Prática de Ensino de } \\
\text { Matemática; Estágio } \\
\text { Supervisionado I e Currículo e } \\
\text { Did. da Mat.: Teoria e Prática }\end{array}$ \\
\hline B & Universidade Federal de Itajubá & & UNIFEI & $\begin{array}{l}\text { Diversas com uma única } \\
\text { referência bibliográfica }\end{array}$ \\
\hline B & \begin{tabular}{|lll} 
Universidade & Federal & do \\
Espírito Santo & &
\end{tabular} & & UFES & $\begin{array}{l}\text { Didática da Mat./Estágio II } \\
\text { Com referências }\end{array}$ \\
\hline $\mathrm{B}$ & $\begin{array}{l}\text { Universidade Federal Rural do } \\
\text { Rio de Janeiro - Seropédica }\end{array}$ & & UFRRJ & $\begin{array}{l}\text { Ens. de Mat. I: Aprendizagem. } \\
\text { Novas Tecnol. Ens.de Mat.I I: } \\
\text { Lúd., Proj. de Trab. e Av. }\end{array}$ \\
\hline $\mathbf{C}$ & Universidade Federal de Alfenas & \multirow{7}{*}{$28 \%$} & UNIFAL & Didática \\
\hline $\mathbf{C}$ & $\begin{array}{l}\text { Universidade Federal de Juiz de } \\
\text { Fora }\end{array}$ & & UFJF & Didática \\
\hline $\mathbf{C}$ & Universidade Federal de Viçosa & & UFV & $\begin{array}{l}\text { Prática de Ensino de } \\
\text { Matemática II }\end{array}$ \\
\hline $\mathbf{C}$ & $\begin{array}{l}\text { Universidade Federal de Ouro } \\
\text { Preto }\end{array}$ & & UFOP & não obrigatória \\
\hline $\mathbf{C}$ & Universidade Federal do ABC & & UFABC & Didática \\
\hline C & 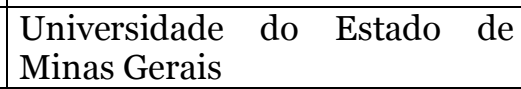 & & UFMG & não obrigatória \\
\hline $\mathbf{C}$ & $\begin{array}{l}\text { Universidade Federal de Minas } \\
\text { Gerais }\end{array}$ & & UEMG & não obrigatória \\
\hline
\end{tabular}

Fonte: sites das diversas IES, acessados em 2017. 
Embora nossa pesquisa tenha sido de natureza qualitativa e exploratória, e a amostra não tenha sido construída visando inferências quantitativas em relação à totalidade dos cursos brasileiros de Licenciatura em Matemática, achamos interessante apresentar os percentuais de cada grupo, para que o leitor tenha uma ideia de referência quantitativa dentro da amostra estudada.

Julgamos que nossa resposta à questão de pesquisa, apresentada sinteticamente no Quadro 1, acima, deve ser complementada com algumas observações:

1. Como nos baseamos apenas em currículos prescritos, não temos garantia de que os saberes constantes das ementas das disciplinas sejam efetivamente aqueles trabalhados no processo de formação do professor de matemática nos programas dessas universidades.

2. Inclusive entre currículos classificados em um mesmo grupo (A, B ou C), há diferenças nas propostas de abordagem do tema. Por exemplo, em alguns currículos, a questão da avaliação da aprendizagem é abordada tanto no contexto geral (independente da área de conhecimento) quanto em relação às particularidades do curso de Licenciatura em Matemática. Em outros, trata-se o tema apenas do ponto de vista geral, independentemente da disciplina Matemática.

3. É preciso observar que, embora 22 dos 25 currículos examinados possuam pelo menos uma disciplina obrigatória em que o tema aparece contemplado em pelo menos um dos tópicos da ementa, apenas 2 (dentre os 25) apresentam uma abordagem relativamente abrangente da temática que foi objeto de investigação.

4. Como mencionado anteriormente, nos últimos anos tivemos mudanças nas grades curriculares de vários cursos de licenciatura em matemática no Brasil. Isso nos levou a revisar, em maio de 2017, os currículos da amostra, o que modificou ligeiramente os resultados que obtivemos a partir da análise dos currículos acessados em 2013. Os ajustes necessários foram efetuados, de modo que os resultados aqui apresentados têm como base os currículos atuais, acessados em 2017.

5. Por fim, observamos que, mesmo nos currículos dos grupos A e B, quase não há referência explícita aos aspectos destacados nas recomendações dos PCN quanto às práticas de avaliação da aprendizagem escolar (por exemplo, a questão da explicitação das expectativas de aprendizagem, nos diferentes ciclos, anos e também em "momentos" dentro de um mesmo ano de escolarização; as tarefas de concretização, para cada escola, dos critérios gerais de avaliação da aprendizagem elencados nos PCN-Matemática; a questão da explicitação de indicadores a serem buscados nas produções dos estudantes para verificação da correspondência efetiva do aprendizado com as expectativas estabelecidas etc.). Isso, no nosso entendimento, pode ser visto como mais uma manifestação concreta do distanciamento entre o processo de formação inicial do professor de matemática da 
Educação Básica e as necessidades de conhecimentos profissionais específicos, postas pela prática docente escolar.

\section{Considerações finais}

Avaliar é uma tarefa que está diante de todos os professores da Educação Básica, quer se acredite na possibilidade de medir a aprendizagem, quer não. Por outro lado, a literatura mostra que há um conjunto de ideias relativas à concepção e ao desenvolvimento de práticas avaliativas escolares que podem orientar a ação do professor em sua sala de aula, embora, muitas vezes, o espaço para implementação dessas ideias não seja totalmente franqueado a decisões exclusivas do professor. Entretanto, no geral, podemos afirmar que um corpo docente bem preparado, com amplo conhecimento teórico e prático sobre a avaliação da aprendizagem escolar, (incluindo a competência no uso de recursos digitais, o que decidimos não comentar neste artigo, para não nos desviar do foco principal) pode influir no formato das decisões institucionais relativas ao tema, trazendo à tona, inclusive, a discussão das recomendações expressas nos documentos oficiais (LDBEN, PCN, Diretrizes Curriculares Nacionais Gerais para a Educação Básica - Brasil, 2013).

A revisão de literatura que fizemos deixa clara também a importância do professor ter contato, em sua formação, com conhecimentos teóricos, com relatos críticos de experiências e com as diferentes concepções a respeito dos efeitos e dos objetivos da avaliação da aprendizagem escolar, a fim de que seja capaz de participar, de forma efetiva e consistente, de ações que visem ultrapassar uma tradição fundamentada na crença de que avaliar a aprendizagem na escola significa medir, com uma nota, a aprendizagem (supostamente mensurável) que ocorreu ou não ocorreu em um determinado período. Outras formas de conceber o papel da avaliação, outros instrumentos e meios possíveis de verificação da ocorrência de maior ou menor progresso do aluno em relação a certos objetivos especialmente importantes da formação escolar, são, quase sempre, vistos como românticos, isto é, potencialmente interessantes, mas inviáveis nas circunstâncias de sala de aula da escola, hoje. E as circunstâncias habituais vão, então, se reproduzindo, num círculo vicioso. Ou, quando muito, levadas ao paroxismo, num processo de progressão automática de ciclo a ciclo, em que a avaliação acaba contribuindo muito pouco, na prática, para um processo efetivo de crescimento intelectual, de amadurecimento cognitivo e de formação escolar do aluno.

Deve-se considerar, por outro lado, que a prática que se estabelece na escola tem suas razões e suportes na sociedade mais ampla, em cuja dinâmica social, econômica e cultural a escola está inserida. Portanto, não acreditamos, ingenuamente, que uma simples mudança nos currículos das licenciaturas possa alterar drasticamente o estado de coisas atualmente vigente na avaliação da aprendizagem escolar. No entanto, acreditamos que mudanças curriculares 
nos cursos de licenciatura em matemática, adequadamente planejadas e executadas, podem desempenhar papel significativo num eventual processo de questionamento das práticas avaliativas vigentes na escola atual. $\mathrm{O}$ questionamento fundamentado tem sempre seus efeitos, no mínimo pode vir a instaurar a dúvida, o que já seria, de certa forma, salutar. Trata-se, assim, de formar o profissional docente capaz, não apenas de executar um processo de avaliação da aprendizagem prescrito, seja pelos documentos oficiais, pela direção da escola ou pela tradição, mas, antes, de discutir esse processo sob uma diversidade de perspectivas, sempre que as oportunidades se apresentem.

O fato é que, até onde as pesquisas empíricas indicam e os documentos oficiais reconhecem, a prática da avaliação da aprendizagem escolar tem sido feita basicamente desconsiderando suas potencialidades educativas e isso constitui uma perda não desprezível no processo de ensino. É preciso levar em conta, ainda, que a avaliação tem implicações fundamentais na vida do estudante, as quais alcançam o próprio desenvolvimento da aprendizagem durante a formação escolar, afetando inclusive, entre outros aspectos dessa formação, as condições de qualificação com que ele competirá futuramente no mercado de trabalho.

No entanto, ao que pudemos concluir a partir desta pesquisa, a formação inicial do professor de matemática mantém uma relação distanciada com os saberes docentes associados à temática da avaliação da aprendizagem em sala de aula da escola. Nossos resultados indicam que, em geral, os currículos das licenciaturas em matemática não incorporam a discussão qualificada a respeito das práticas avaliativas vigentes nas salas de aula da escola nem o estudo aprofundado da viabilidade teórica e prática de formas e instrumentos alternativos de avaliação da aprendizagem. Apenas dois, em um total de 25 currículos de instituições públicas examinados ( $8 \%$ da amostra) atribuem, segundo nossa categorização, Relevância Alta ao tema na formação do professor de matemática da Educação Básica, mesmo considerando que esse patamar (Relevância Alta) foi definido a partir de condições relativamente pouco exigentes: basicamente, a potencial abordagem de um conjunto de tópicos sobre o tema "avaliação da aprendizagem escolar”, conjunto esse extraído da literatura especializada.

Há que se levar em conta, certamente, as dificuldades próprias da construção de qualquer currículo de formação profissional. Sabemos que é praticamente impossível elaborar um projeto curricular que se proponha a desenvolver de forma totalmente abrangente todas as discussões relevantes encontráveis na literatura sobre um tema como a avaliação da aprendizagem escolar. Escolhas e contingenciamentos são inevitáveis. Entretanto, os demais currículos examinados (mais de 90\% da amostra) deixam à deriva importantes reflexões sobre essa temática. Nosso ponto de vista quanto às implicações de uma formação deficitária para a prática docente já foi exposto: não se trata de concluir que uma formação inicial abrangente, 
profunda e crítica vá, automaticamente, produzir mudanças radicais nas práticas avaliativas habituais nas escolas, hoje. Mas pode, seguramente, contribuir para que o professor tenha condições de, nos espaços que se apresentem em sua prática profissional, criticar, adaptar, reformular e propor alternativas às formas e instrumentos de avaliação, de modo a torná-los mais eficientes em relação ao desenvolvimento da aprendizagem escolar e, consequentemente, mais consistentes com os objetivos explícitos da educação escolar básica.

\section{Referências}

Arnal-Bailera, A.; Cid, E.; Muñoz-Escolano, J.M.; Oller-Marcén, A.M. Marking mathematics exams as a tool for Secondary Teacher Education. 13th International Congress on Mathematical Education Hamburg, 24-31, Julho, 2016.

Baldino, R. R. Avaliação e seus adjetivos. Palestra apresentada na Escola de Engenharia de Guaratinguetá, 1994 (mimeo)

Baldino, R.R. Assimilação solidária onze anos depois. Unesp/Rio Claro (mimeo), 1995.

Bloom, B.; Engelhart, M.; Furst, E.; Hill, W.; Krathwhol, D. Taxonomia de objetivos educacionais. Porto Alegre: Globo, 1977.

Brasil, 1996. Lei de Diretrizes e Bases da Educação Nacional. Acessível em http://www.planalto.gov.br/ccivil_03/Leis/L9394.htm

Brasil, 1997. Parâmetros Curriculares Nacionais para o Ensino Fundamental - $\mathbf{1}^{\mathrm{a}}$ a $4^{\text {a }}$ séries. Acessível em: portal.mec.gov.br/seb/arquivos/pdf/livroo1.pdf

Brasil, 1998. Parâmetros Curriculares Nacionais - Terceiro e Quarto Ciclos do Ensino Fundamental - Matemática: acessível no seguinte endereço (último acesso em abril de 2017): portal.mec.gov.br/seb/arquivos/pdf/matemática.pdf

Brasil, 2001a. Diretrizes Curriculares Nacionais para a Formação de Professores da Educação Básica, em nível superior, curso de licenciatura, de graduação plena. Acessível em: portal.mec.gov.br/cne/arquivos/pdf/oog.pdf

Brasil, 2001b. Diretrizes Curriculares Nacionais para os Cursos de Matemática,

Bacharelado e Licenciatura: portal.mec.gov.br/cne/arquivos/pdf/CES13022.pdf

Brasil, 2013. Diretrizes Curriculares Nacionais Gerais para a Educação Básica: http://portal.mec.gov.br/docman/julho-2013-pdf/13677-diretrizes-educacaobasica-2013-pdf/file

Enguita, M. F. A Face Oculta da Escola: Educação e Trabalho no Capitalismo. Porto Alegre: Artes Médicas, 1989.

Hoffmann, J. Avaliação Mediadora: Uma Prática da Construção da Pré-escola a Universidade. $20^{\mathrm{a}}$ ed. rev. Porto Alegre: Mediação, 2003. 
Kajander, A.; Holm, J.; Chernoff, E.J. Teaching and Learning Secondary School Mathematics. Cham (Switzerland): Springer, 2018.

Leuders, T.; Philipp, K.; Leuders, J. (eds). Diagnostic Competence of Mathematics Teachers: Unpacking a Complex Construct in Teacher Education and Teacher Practice. Basel (Suíça): Springer, 2018.

Lopes, S.L. A função da avaliação e o habitus corporificado em sala de aula. Revista Fórum Identidades, Ano 10, Volume 22, n. 22 | set-dez, 2016.

Luckesi, C. C. Avaliação da aprendizagem escolar: estudos e proposições. $22^{\mathrm{a}}$ ed. São Paulo: Cortez, 2011.

Nortvedt, G.A.; Buchholtz, N. Assessment in mathematics education: responding to issues regarding methodology, policy, and equity. ZDM Mathematics Education, vol.50, n.4, p.555-570, Agosto, 2018.

Radford, L. Signs, gestures, meanings: algebraic thinking from a cultural semiotic perspective. Plenary Lecture Sixth Conference of European Research in Mathematics Education (CERME 6). Université Claude Bernard, Lyon, France, 2009.

Radford, L. Layers of generality and types of generalization in pattern activities. PNA, 4(2), 37 - 62, 2010.

Radford, L. Grade 2 students 'non-symbolic algebraic thinking'. In J. Cai \& E. Knuth (Eds.), Early Algebraization. Berlim: Springer, 2011.

Tyler, R. W. Basic Principles of Curriculum and Instruction. Chicago: The University of Chicago Press, 1949.

Vieira, L. A. G. A avaliação como Instrumento de Promoção da Aprendizagem. Monografia de Especialização em Educação Matemática. Ouro Preto: Universidade Federal de Ouro Preto, 2006.

\section{Biografia Resumida}

Nilson de Matos Silva: Formação inicial: Licenciatura em Matemática pelo Instituto Superior de Educação Anísio Teixeira da Fundação Helena Antipoff (ISEAT-FHA). Mestre em Educação Matemática, pela Universidade Federal de Ouro Preto (UFOP - Campus Ouro Preto). Atualmente é Chefe do Departamento de Ciências Exatas e Professor da Licenciatura em Matemática da Universidade do Estado de Minas Gerais (UEMG Ibirité). Integrante do Grupo de Pesquisa "Laboratório de 
Estudos sobre a Docência” (LEDOC-UEMG Ibirité).

Contato: nilson.matos@uemg.br

Link do lattes: http://lattes.cnpq.br/7748185355239793

Plínio Cavalcanti Moreira: Bacharel em Matemática pela Universidade Federal de Minas Gerais (UFMG/Campus Pampulha), Mestre em Matemática pela UFMG/Campus Pampulha, BH; Doutor em Educação pela UFMG/Campus Pampulha, BH; Pós-Doutorado na Universidade de Alicante, Espanha. Atualmente é Professor da Universidade Federal de Ouro Preto (UFOP/Ouro Preto, MG).

Contato: pliniocavalcantim@gmail.com

Link do lattes: http://lattes.cnpq.br/2548887509034427 